\title{
Vision, Challenges and Solutions in the Development of Professional Social Work in Vietnam: Perceptions of Key Stakeholders
}

\author{
Huong Nguyen ${ }^{1}$, Trang Thu Nguyen ${ }^{2}$, Naomi Farber $^{3}$ \\ ${ }^{1} \mathrm{PhD}$, MSW, MA, Assistant Professor in the College of Social Work at University of South Carolina, United States \\ ${ }^{2}$ Doctoral Student at the College of Social Work, University of South Carolina, United States \\ ${ }^{3} \mathrm{PhD}$, MSW, Associate Professor in the College of Social Work at University of South Carolina, United States \\ Correspondence: Huong Nguyen, PhD, MSW, MA, Assistant Professor in the College of Social Work at University of \\ South Carolina, United States.
}

Received: January 4, 2017

doi:10.11114/ijsss.v5i3.2121
Accepted: February 13, 2017

Available online: February 15, 2017

URL: https://doi.org/10.11114/ijsss.v5i3.2121

\begin{abstract}
It was not until 2010 that social work was officially recognized as a profession in Vietnam when the government approved a national master blueprint to develop social work. This blueprint identified seven strategic objectives including: creating a foundational labor force, developing laws and policies, and raising awareness about social work. This exploratory study examines the degree to which key stakeholders in Vietnam have shared vision and perceptions about the challenges and solutions necessary to make this ambitious plan for Vietnamese social work succeed. An anonymous survey was conducted with 65 policy makers, educators, service providers, and practitioners. The survey revealed that key stakeholders in held a shared vision about Vietnamese social work, focusing on making it a genuine profession. They identified the top challenges for Vietnamese social work as lack of national policy and regulations, lack of public awareness about the profession, and lack of resources to develop high quality social work education. Key stakeholders considered social work to be an integral function of the government and, as such, depend upon the government to lay the foundation for, provide direction to, and make available the resources necessary for the profession to grow. In other words, there would not be a Vietnamese social work profession outside of and without the Vietnamese government, unlike how the social work profession has developed in many western countries.
\end{abstract}

Keywords: Vietnam, social work, vision, challenges and solutions

\section{Introduction}

Like a traveler who needs a clear final destination before embarking on a journey, a developing profession should be founded on a distinct vision in order to progress effectively, minimize wasted efforts, avoid detours, or even depart from the path. The journey is made smoother when its members anticipate obstacles and are able to form solutions for the likely hurdles. In the case of the emerging profession of social work in developing countries such as Vietnam, the need for key stakeholders to have shared vision and common understanding of possible challenges and their solutions is particularly important for two reasons.

First, this shared vision can enhance consistency in accomplishing a wide range of foundational activities such as building governmental laws and policies, establishing educational standards and codes of ethics, creating national and local service delivery systems, and promoting common discourse about social work within the general public. Second, this shared vision can help in resisting wholesale "the dominance of the Western paradigm" and in developing a truly indigenous profession that fits the Vietnamese context and serves Vietnamese people (Brydon \& Lawihin, 2016, p. 192). The latter has become increasingly significant because contemporary Vietnam is unique in its position as one of the only remaining communist countries in the world, economically a market economy but culturally embedded in Confucianism, Taoism, Buddhism, and local beliefs. Many developed countries with longer histories of formal social welfare systems of care provide important lessons and models relevant in their own contexts. However, Vietnam must be cognizant of the complex issues raised by global debates regarding "globalization versus localization, Westernization versus indigenization, multiculturalism versus universalism, and universal versus local standards" in developing social welfare 
systems of policy and practice (Brydon \& Lawihin, 2016, p.192). Despite a burgeoning service and educational infrastructure supporting professional growth, there has been no systematic investigation of perceptions of key stakeholders and leaders regarding the most fundamental issues for Vietnamese social work. Primary among these are: what the profession might look like in 20 and 50 years after the formative decades have passed; what challenges lie ahead in reaching the government's 20-year and 50-year vision; and what solutions may exist for overcoming these challenges. In this exploratory study, we begin to fill this knowledge gap by asking two questions:

Question 1: What do Vietnamese policy-makers, social work educators, and practitioners perceive as the vision, challenges, and solutions for Vietnamese social work?

Question 2: Is there a consensus among Vietnamese policy-makers, social work educators and practitioners about the vision, challenges, and solutions for social work in Vietnam?

\section{BACKGROUND: SOCIAL WORK IN VIETNAM}

Following a long history with a rich tradition of community- and family-based altruism, Vietnam began developing its social work profession only recently. For hundreds of years, families and local communities were primary sources of support for people in need of help (Oanh, 2002). Tens of thousands of Buddhist temples embedded in every village also played a significant role in providing food, shelter, counseling, and spiritual support for individuals, families, and whole communities (V. H. Nguyen, 2014).

In modern times, between the end of the Vietnam War and the early 2000s, service provision remained primarily informal Formal social services were provided only for the very poor or those severely physically and mentally affected by the war. It was not until 2010 that the term "social work" was re-introduced into national public discourse when the Vietnam Prime Minister approved Decree 32 about Developing Social Work Profession in Vietnam (Oanh, 2002; V. H. Nguyen, 2009; V. H. Nguyen, 2014). Table 1 summarizes key milestones in the history of Vietnamese social work.

Table 1. Key Milestones in Vietnamese Social Work History

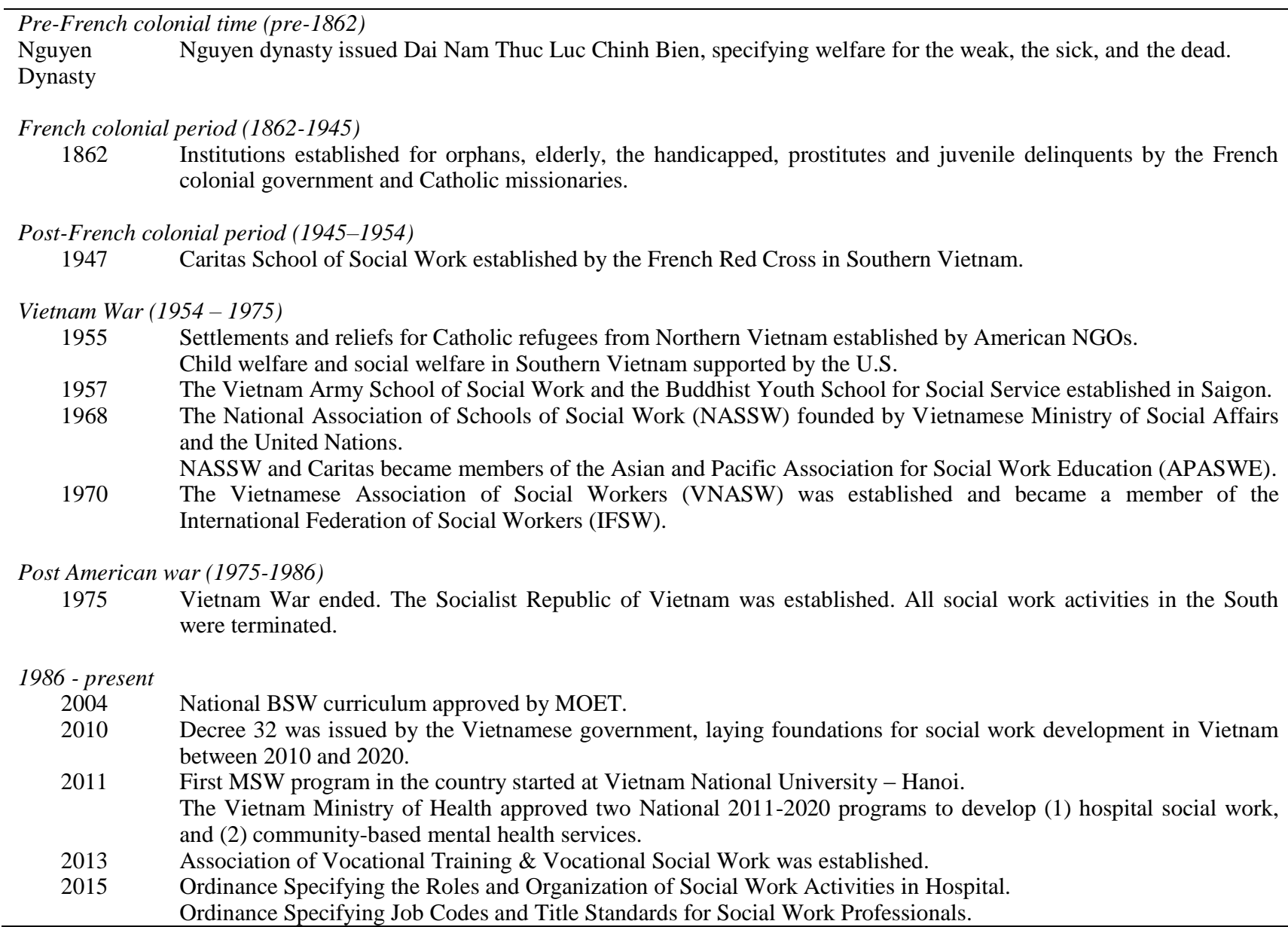

The very term "social work" (cong tac xa hoi) in Vietnamese can be misunderstood as primarily political-social activities since, translated literally, it might signal social movements, revolutions, protests, community works, union movements, and similar ideas. Consequently, one of the main goals of Decree 32 for the 2010 - 2015 period was to improve 
knowledge by key stakeholders and the general public in Vietnam about what professional social work is, how it can enhance wellbeing, and how to gain access to its benefits (V. H. Nguyen, 2014).

In the five years following Decree 32, the Vietnamese government issued 18 national policy documents, numerous manuals, and instructions, providing guidance to implement the policies. Many of these government edicts proposed very ambitious goals. For example, in July 2011, the Vietnam Ministry of Health passed the Decision to Develop Health Social Work, which planned to place social work services in $80 \%$ of central-level hospitals, $60 \%$ of province-level hospitals, $30 \%$ of town/district-level hospitals, and $40 \%$ of commune clinics by 2015 , despite the absence of training programs in health social work across the nation then or now (Ministry of Health, 2011). Between 2010 and 2014, six new comprehensive social work centers were established in big cities and provinces and nearly 9,000 social workers registered as members of local social workers' networks (Nguyen, 2014).

Parallel with these laws and policies, social work education blossomed with disquieting speed. By the end of 2015, there were approximately $40 \mathrm{BSW}$ programs and four MSW programs across the nation, producing roughly 2,500 graduates each year (Ngo, 2009; H. Nguyen, 2013, 2014; H. T. K. Nguyen, 2011; L. T. T. Nguyen, Hugman, \& Briscoe, 2010; Nguyen V. H., 2014). The first two PhD programs were both approved for recruitment in 2015 at Vietnam National University and Vietnam Academy of Social Sciences. Key stakeholders included a few big universities in Hanoi and Ho Chi Minh City such as Vietnam National University - Hanoi and Ho Chi Minh City, Hanoi National University of Education, University of Labor and Social Affairs, Thang Long University, Trade Union University, Vietnam Academy of Women, Vietnam Youth Academy, and others. International organizations such as UNICEF, Atlantic Philanthropies, or Vietnam Assistance to the Handicapped (VNAH) have also been instrumental in advancing social work through funding Vietnamese government and universities in projects related to social work policies and training programs.

The central government of Vietnam, especially the Ministry of Labor, Invalids, and Social Affairs (MOLISA) under the direction by the Prime Minister, has been playing the leading role in the development of Vietnamese social work. This charge to MOLISA includes developing a Code of Ethics, practice standards, licensure, and employment and salary standards for social workers. Working in tandem with MOLISA, the Ministry of Education and Training (MOET) is in charge of developing curriculum requirements and accreditations; the Ministry of Health (MOH) is in charge of issues related to the intersection between social work and health; and the Ministry of Internal Affairs is responsible for creating job titles and salary standards for social work professionals for the existing governmental job system.

Despite these exciting developments in the social work scene in Vietnam, it is unclear at the end of the 2010-2015 period whether the most important of these stakeholders have reached a shared understanding of the vision of the profession, the challenges facing its development, and solutions to these challenges in developing Vietnamese social work. Limited available research suggests cause for concern over the actual status of social work practice in key settings despite the formal directives and vigorous programs of education.

2. Methods

\subsection{Data Collection}

Data were collected in June 2014 at a major international conference on the development of social work in the area of mental health in Vietnam, currently a governmental priority. Three groups of participants were invited: (1) policy-makers from central government agencies related to social work, including MOLISA, Vietnam Ministry of Education and Training (MOET), and Vietnam Ministry of Health (MOH); (2) university administrators, department heads, and faculty members from social work training programs in Vietnam; and, (3) practitioners and other stakeholders from local service agencies, hospitals and healthcare organizations, international and local non-governmental organizations. Approximately 100 people attended the conference.

The authors consulted with the Vietnamese conference organizers to determine procedures that would secure maximum participation without compromising the integrity of the conference or data collection. Based on this plan, IRB approval was obtained from the University of South Carolina.

\subsection{Materials}

The primary investigator, a native speaker of Vietnamese, developed a draft Vietnamese-language survey questionnaire, which was revised in consultation with American and Vietnamese social work faculty and researchers constituting the conference planning committee. The survey contained four sections. The first section included participants' basic demographic information such as gender, job, education, and the relation of their job to social work (policy-makers, university administrators, social work faculty, practitioners, potential employers of social workers, or others). The second section consisted of eight questions eliciting participants' opinions on the mission, core values, and culturally unique characteristics of Vietnamese social work. This section also asked participants to envision Vietnamese social work in the next 20 and 50 years, as well as the challenges and solutions to developing social work in Vietnam. The third and fourth 
sections asked participants for their opinions on the needs, challenges, and solutions to developing training programs in mental health social work. Questions were primarily multiple-choice, mixed with open-ended questions, written in simple language to make sure that even participants not familiar with social work could understand. The survey consisted of 40 questions and took about 30 minutes to complete.

\subsection{Procedures}

At the opening of the conference all participants were given a registration packet that included the survey and informed consent form, information about the study, and instructions about how to complete and submit the survey by the end of the day. Included with the instructions was written assurance that participation was strictly voluntary and that respondents would remain anonymous. Participation was facilitated by including a 30-minute session at the end of the morning sessions dedicated to completing the surveys, as well as scheduled breaks after lunch and then mid-afternoon. Providing time during the conference to complete the surveys was deemed a way to respect the time of the participants, all of whom were busyprofessionals.

\subsection{Data Analysis}

Survey data were entered into SPSS. Quantitative data were analyzed using IBM SPSS Statistics 22 Package. Besides examining participants' current positions, education, and the relationship of their jobs toward social work profession, we primarily ran descriptive analyses to understand the overall picture and distribution of participants' responses to the survey questions regarding the vision, challenges, and solutions to the development of Vietnamese social work. Qualitative data were transferred into an Excel file since most open-ended answers were rather short. Two researchers then used thematic analyses to analyze data independently. We first familiarized ourselves with the data and how participants answered the questions. We then used the research questions as the conceptual guidance to develop initial themes from the answers of participants. Based on these themes, meta themes were developed regarding the vision, challenges, and solutions to the development of social work in Vietnam in the next decades.

\section{Results}

\subsection{Sample Description}

Sixty five (65) participants completed the survey. Table 2 provides demographic descriptions of the participants. Females accounted for $63 \%$ of the participants. Approximately $60 \%$ of participants were faculty and/or administrators at universities or colleges providing social work education, resulting in nearly $50 \%$ of the participants holding doctoral degrees and $37 \%$ master's degrees. The rest of the participants were affiliated with governmental organizations making policies about the social work profession (19.1\%), agencies employing social workers (17.5\%), or funding agencies.

Table 2. Demographic Descriptions of Key Stakeholders in Vietnamese Social Work $(\mathrm{N}=65)$

\begin{tabular}{lrr}
\hline & & (Valid) $\%$ \\
\hline Demographic Variables & 41 & 63.1 \\
\hline Gender & 24 & 36.9 \\
Female & 30 & 46.2 \\
Male & 24 & 36.9 \\
Education & 11 & 16.9 \\
PhD & 9 & 14.3 \\
Master's degree & 3 & 4.8 \\
Bachelor's degree & 38 & 60.3 \\
Institutional affiliation & 11 & 17.5 \\
Governmental agencies making policies about social work profession or welfare & 6 & 9.5 \\
Governmental agencies making policies in social work education & 5 & 7.5 \\
Social work training institutions & & \\
Agencies employing social workers & 31 & 47.7 \\
Agencies providing financial and other support to social work development & 9 & 13.8 \\
Others & 8 & 12.3 \\
Job position & 8 & 12.3 \\
Faculty and instructors of social work & 9 & 13.8 \\
Policy-makers, managers, supervisors & 9 \\
Educational administrators & & \\
Non-governmental organizations' officers & & \\
Others & & \\
\hline
\end{tabular}

Among 39 participants who were currently social work faculty, 24 (61.5\%) did not have a terminal degree in social work and only one had a doctoral degree. However, nearly $100 \%$ of them had received some training in social work, with approximately $40 \%$ receiving less than 2 years of cumulative training, 33\% between 2 and 4 years, and $26 \%$ more than 6 years. With regard to training in social work practice, about $47 \%$ received cumulative training for less than 1 year, $12 \%$ between 1 and 2 years, and $41 \%$ more than 2 years. When asked to rate how confident they were in their competence when 
teaching social work courses, with 0 being "not at all confident about my competence" and 10 being "very confident about my competence," $58 \%$ of respondents gave themselves at least a rating of 7 . However, when asked to rate the quality of social work education in Vietnam from 0 to 10 , with 0 being "very low quality" and 10 being "very high quality," $60 \%$ gave the rating of 5 or below. The majority of them wished to receive further education in social work but strongly preferred short-term training such as certificate programs on specific skills and knowledge rather than long-term training leading to terminal advanced degrees.

\subsection{Vision for Vietnamese Social Work in 20 and 50 years}

To explore key stakeholders' visions for Vietnamese social work, we asked participants to envision the profession of social work in Vietnam in 20 and 50 years. We selected 20 years since it would give enough time for Vietnam to address foundational issues such as creating the mission and identity of the profession, code of ethics, training program accreditation and licensing standards and procedures. In addition, within 20 years social workers should be placed where they are most needed, according to how key stakeholders and the society in general envision their roles. We selected 50 years as the second milestone as it would give enough time for social workers in Vietnam to assess and respond to early developmental problems departing from the professional ideals identified by current key stakeholders. For the 20-year milestone, they would be able to take into consideration the current political, economic, and social context that shapes the development of social work. For the 50-year milestone, participants would be able to think about the social work profession without the current political, economic, and social constraints; that is, they would be able to truly dream about the profession in its ideal form. For both timeframes, participants were asked to complete three open-ended statements describing what they envisioned for the profession, for social workers, and for social work education. The prompts included:

In 20 years I see social workers at...

In 20 years, I see [Vietnamese] society recognizing the social work profession as...

In 20 years, I see social work training programs...

We specifically wanted to focus on the three above-mentioned visions because they addressed central issues that key stakeholders and Vietnamese society struggle with at present: What are the roles and activities of the social work profession? What are the roles of social workers? Where do social workers work? What does social work education in Vietnam look like? We also wanted to leave the prompts open to be able to cover the potential wide range and variance in respondents' answers.

The 20-year vision: Social work as a profession and governmental function. More respondents answered the question about their 20-year vision than their 50-year vision for Vietnamese social work- $92 \%$ compared to $77 \%$. Since most participants went on to complete the rest of the survey, it is likely that they intentionally left blank the question on 50-year vision, perhaps because they lacked a clear answer to the question.

Analysis of the survey results reveals that key stakeholders developed a beginning shared vision about Vietnamese social work in 20 years. The most common statements suggested a vision in which social work would become an established profession, even "a core profession" playing an "essential," "vital" role in Vietnamese society. This vision was expressed through very positive predictions about the profession, social workers, and social work education, implying that the social work profession was the answer to all current social problems in Vietnam and would be recognized as such:

"I see social workers everywhere across the country and in every area of human life" (Faculty)

"I see social workers present everywhere, anywhere that has difficulties, anywhere that needs spiritual/mental/emotional support." (Faculty)

"I see [Vietnamese] society recognizing the social work profession as indispensable" (Policy-maker)

"I see society recognize social work profession as must-have profession because social work is the solution to social problems." (Faculty)

"I see society recognize social work profession as one of the most important, most valuable professions in society." (NGO staff)

"I see social work schools as trustworthy training institutions, providing social workers that have ethics, virtues, knowledge, and skills to work professionally." (Faculty)

"Professional" was present in most stakeholders' statements, either explicitly or implicitly. "Professional" was understood as having a transparent, democratic, and efficient organizational structure and mechanisms, standards, activities, and evidence-based practices that would be followed and shared universally by social workers, social work 
employers, social work training programs, and the general society. This conceptualization of professionalism expresses a Western idea in contrast to a more traditional Vietnamese idea of professionalism, which centers around social hierarchy, morality, and honor. "Professional" was also understood as a career that would "provide stable income and social status" for social work practitioners-another idea imported into Vietnam in 1986 with the adoption of the market economy. Stakeholders envisioned social workers to be present in many settings and contexts where they are not now, such as hospitals, court systems, schools, prisons, and disaster relief. Some envisioned that social workers would be present in the National Assembly of Vietnam, while others saw social workers present in companies, factories, industrial zones, potentially with the same function as trade unions. One participant envisioned that in 20 years social workers would be present "in my home," though it was unclear if s/he was using a figure of speech to mean that social workers would be present in every Vietnamese family in need. This highly optimistic vision about Vietnamese social work echoed much of the enthusiasm about the adoption of communism/socialism in Vietnam after the Vietnam War. It should be noted that many key stakeholders had backgrounds as activists during and after the wars, thus they were likely to be familiar with that type of fervor. Their responses also indicated that key stakeholders in Vietnam largely saw the profession of social work as a public structure organized and operated by the Vietnamese government with social workers being primarily governmental staff. In other words, the Vietnamese social work profession would be a comprehensive governmental function aimed at fixing each and all Vietnamese social problems.

The 50-year vision: Social work as an established profession with global reach. The vision for Vietnamese social work in 20 years and 50 years did not seem to differ much for most participants. Many simply copied the statements they had for 20-year visions or modified it slightly to indicate that in in 50 years, social work would be "more established" to be present "everywhere." Some stated that they envisioned the scope of social work to expand from typical settings such as schools and hospitals to companies and residential areas, indicating the hope that over time, social work would be serving all Vietnamese individuals, families, and communities rather than focusing only on the most needy and vulnerable. With regard to social work education, participants envisioned that in 50 years, social work schools in Vietnam would also have research activities rather than just providing training as they do at present. Overall, "being professional" remained the most salient theme in stakeholders" vision for social work development in the next five decades. The continued emphasis on social work becoming a profession that would be "recognized as a prestigious career like doctors, lawyers, or engineers" indicated a shared understanding among stakeholders that currently social work is only beginning to develop in Vietnam and that there remains much ambiguity in what the profession should look like, its status, what social workers do, and how to train social workers well. It also implied regretful acknowledgment that Vietnamese social work was not yet on a par with social work profession in other countries. A few participants hoped that in 50 years, social work education in Vietnam would have "network[ed] with the whole world" and would be "recognized by the world."

Vision of social work faculty vs. other stakeholders. There were patterns among different groups with regard to the vision of Vietnamese social work. Participants affiliated with universities and/or having doctoral degrees had more consensus in their vision about social work, with most of them emphasizing the vision for Vietnamese social work profession per se and for social workers to become professional. Yet, they seemed less optimistic about the possibility of Vietnamese social work becoming a profession in 20 years (24\%), compared to participants working for non-governmental organizations (63\%). Their statements emphasized making social work education "more practical," reflecting the general concern that social work education in Vietnam did not focus enough on field practice due to a severe lack of faculty with practical experience, field agencies, and supervisors.

These differences suggested that what stakeholders envisioned for Vietnamese social work was influenced by their direct experiences with social work and reflected, on the one hand, what they predicted as the reality of Vietnamese social work in the future and, on the other hand, what they wished would happen. Faculty and university administrators might have a deeper understanding about the logistical barriers (i.e., what educational laws and policies need to be passed before they can start training) as well as professional barriers (e.g., lack of social work faculty, teaching materials, and field agencies) that need to be overcome to make social work education in Vietnam become professional, and thus they might be more conservative in their vision. In contrast, stakeholders from NGOs who hope to hire social workers are more likely to envision in a wishful way that social work education would be able to produce competent social work graduates.

Even though the majority of participants envisioned a positive picture for Vietnamese social work in 20 and 50 years, a few painted a less optimistic picture. These negative statements focused primarily on the 20-year vision for social work education and how Vietnamese society would view social work. For example, participants were concerned that in 20 years, the society would see the social work profession as a "confusing profession" or a "charity-providing profession." Others worried that society would mistake social work profession for "union activities," which is a common misunderstanding at present due to the Vietnam Communist Party's legacy of establishing trade unions, women's unions, 
youth unions, and veterans' unions in every organization and residential neighborhood in Vietnam. Eight participants envisioned that in 20 years, social work education in Vietnam would continue to lack qualified faculty and other resources needed to produce competent social workers. For example, one participant stated that in 20 years, he saw social work schools in Vietnam to "have tried their best but still lack knowledge and experiences in order to provide professional, high-quality training," while another expressed concern that social work schools would not be able to train enough workers "to work in every aspect of social life in Vietnam, including companies, factories, and enterprises."

\subsection{Challenges and Their Solutions to Vietnamese Social Work}

To explore key stakeholders' perceptions about possible barriers, we asked them to identify the three biggest challenges for the development of Vietnamese social work. Participants were then asked to list the three most important activities that could overcome the three top challenges identified earlier. Table 3 summaries participants' answers to these two questions.

Table 3. Biggest challenges of and suggested solutions for Vietnamese social work $(\mathrm{N}=65)$

\begin{tabular}{|c|c|c|c|}
\hline Challenges & $\mathrm{n}$ (valid \%) & $\begin{array}{rr}\text { Strategies } \\
\end{array}$ & $\mathrm{n}($ valid \%) \\
\hline Lack of policy for social work profession & $30(46.2)$ & $\begin{array}{l}\text { Improve policies } \\
\text { profession }\end{array}$ & $40(61.5)$ \\
\hline $\begin{array}{l}\text { Limited awareness of social work as a } \\
\text { profession }\end{array}$ & $28(43.1)$ & $\begin{array}{l}\text { Improve public awareness of social work by } \\
\text { propagandas }\end{array}$ & $19(29.2)$ \\
\hline Limited educational quality & $27(41.5)$ & $\begin{array}{l}\text { Enhance quantity and quality of training } \\
\text { programs in social work }\end{array}$ & $48(73.8)$ \\
\hline Insufficient and low-quality social workers & $26(40.0)$ & & \\
\hline
\end{tabular}

Challenges to Vietnamese social work. Overall, there was strong agreement among participants regarding the biggest challenges for Vietnam in developing the social work profession. Nearly half of the participants considered the biggest challenge for Vietnamese social work to be a lack of national policies regulating the social work profession, including policies about where social workers would work, what official titles and associated training credentials they would have, and what their salary ranges would be. This concern once again indicated that the majority of key stakeholders considered the social work profession as a governmental function, implying that the profession's development was highly dependent on guidance and regulations from the government. They did not seem to envision another pathway common among Western countries: that is, an autonomous social work profession developing on its own and largely self-regulating, emerging from identification of the needs and grassroots activities of local communities. Nor did they seem to think that the profession could be developed independent of the central government. It should be noted further that social work faculty and practitioners were more likely than policy-makers to identify lack of policy as the biggest challenge for Vietnamese social work.

Participants agreed that the second biggest challenge for the development of Vietnamese social work was a lack of public awareness about the profession. Most social work educators and practitioners expressed the concern that Vietnamese society often misperceived social work services as charitable activities reserved for only the neediest, for example disabled or very poor people; thus, people did not reach out to social workers when they needed help (Hines et al., 2010; Mai, 2011). They were also concerned that authorities at different levels of governance were not aware of social work and would not support the development of social work.

"The public does not understand what they can benefit from social work services". (NGO staff)

"The public and the governmental authorities at different level of governance are not aware of social work." (Social work faculty)

The quality of social work training was also considered another major challenge to the development of Vietnamese social work. Once again, social work faculty and education administrators were more concerned about low quality of social work training than policy-makers or practitioners. Finally, participants also found the current lack of human resources in general (for example, qualified social work faculty and practitioners, consultants, or policy-makers with deep knowledge about social work) another challenge for the development of Vietnamese social work.

Solutions to challenges facing Vietnamese social work. When asked to list the top three solutions to the challenges identified, most participants provided very brief and generic statements, such as "[improve] human resource," "teaching materials," and "propaganda [to raise public awareness]." The solutions identified by participants corresponded directly to the top challenges identified. Specifically, developing national policies to regulate the profession was considered the most important solution to ensure the development of Vietnamese social work. Participants were particularly keen on the government taking the leading and decisive role in tackling these challenges through issuing policies. However, participants rarely made clear what policies were needed.

"Advocate for policy and law changes." (Social work faculty).

"Policy for social work profession." (Social work faculty). 
"Issue policy for social worker positions in the job system." (Social work faculty).

"Develop policies and job benefits for social workers." (Social work faculty)

Other solutions to social work development included improving public awareness about the social work profession and strengthening social work education in order to produce competent social workers. Many participants seemed to think that the root solution for all problems in Vietnamese social work lie in improving social work training. Here, participants provided more concrete ideas, including reforming the curriculum, developing more teaching materials, and improving the quality of social work faculties.

"Design proper curricula and teaching materials such as those of developed countries in the world." (Policy-maker)

"Develop social work faculties." (Social work faculty)

"Focus on practice training." (Policy-maker)

\section{Discussion and Conclusion}

Our objective in conducting this exploratory study was to carry out an initial assessment of the degree to which key stakeholders in Vietnam shared a vision about the development of Vietnamese social work, five years after the landmark Decree 32 . The study also aimed at assessing whether key stakeholders have shared perceptions about major challenges and solutions to realize the vision. Analysis of data suggests that key stakeholders influencing Vietnamese social work have a shared vision that reflects the hope that social work will become a developed profession over the next few decades. They saw the biggest challenges for the development of Vietnamese social work being a lack of national policy and regulations, lack of public awareness about social work, and lack of human and financial resources essential to establish quality social work education. They believe that the government should and will play a big role in tackling these challenges by issuing national social work laws and regulations, raising public awareness, and investing in social work education.

One prominent theme present in the findings of this study is the strong role of the central government in developing social work in Vietnam. Key stakeholders consider social work to be an integral function of the government and as such depend upon the government to lay the foundation for, provide direction to, and make available the resources necessary for the profession to grow. In other words, there would not be a Vietnamese social work profession outside of and without the Vietnamese government. This represents a rather different approach to the development of the social work profession from that of other, particularly Western countries. In the US, for example, the profession developed more autonomously from the federal and state governments, evident, for example, in the early leadership provided by individuals like Mary Richmond and Jane Addams. Social workers and the identified needs of citizens significantly shaped the growth of the profession through independent professional bodies such as the National Association of Social Workers, the Council on Social Work Education, and the Society for Social Work and Research.

Another noteworthy finding from the study is that the key stakeholders unanimously wish to see Vietnamese social work become a genuine profession. While this might seem obvious to social work scholars and practitioners elsewhere in the world, it actually signifies a fundamental shift in the attitudes of Vietnamese people with regard to social services. For centuries, informal help provided by families, neighbors, and faith-based organizations (for example, Buddhist temples) has been the primary source of support for people in need. As such, help is never conceptualized as a service, let alone a paid service, but an act of kindness coming out of compassion and a moral code. Kindness and volunteerism are hallmarks of helping activities. When the Socialist Republic of Vietnam was established, welfare was reserved only for special groups such as severely disabled and poor people, with no system of social and human services for the general public. Given that participants in this study unanimously see the need to make social work incorporate a formal body of professional activities signifies a new desire to create services that can reach the general public and are organized in the form of institutionalized structures. That is, Vietnamese society is becoming open to seeking help from paid professionals for psychosocial therapies and other social services instead of shying from it as some literature previously indicated (Ham, Wright, Van, Doan, \& Broerce, 2011; Nguyen and Anderson, 2005; Phan, 2000). This is a new perspective that comes with accelerating globalization in Vietnam. The idea of social work as a profession and the concept of professionalism are influenced by Western ideas, which emphasize a knowledge base, specialized skills, and credentials (Austin, 1983).

Although social work as a profession is new in Vietnam, the country is quickly adopting ideas about practice standards, a code of ethics, licensure, accreditation and other contemporary characteristics of a bona fide profession. This coincides with globalization of the social work profession and social work education, a process which often draws on models based on the institutions, perspectives, values, and particular histories of Western societies. It is clear that leaders in Vietnam are keen on making social work an effective and valued profession. At the same time, there remains an urgent challenge to incorporate from this tradition relevant knowledge and insight while steering the profession toward the unique needs of Vietnam, consistent with its own cultural heritage and current socio-political context. 


\section{Acknowledgements}

The Walker Institute of International and Area Studies at the University of South Carolina provided funding for the research project based on which this paper is written.

\section{References}

Austin, D. (1983). The Flexner myth and the history of social work. Social Service Review, 57(3), 357-377. https://doi.org/10.1086/644113

Brydon, K., \& Lawihin, D. (2016). Melanesian visions? Some preliminary thoughts about social work education and practice in Papua New Guinea. International Social Work, 59(2), 192-204. https://doi.org/10.1177/0020872813515012

Ham, L., Wright, P., Van, T., Doan, V. and Broerse, J. (2011). Perceptions of Mental Health and Help-Seeking Behavior in an Urban Community in Vietnam: An Explorative Study. Community Mental Health Journal, 47(5), 574-582. https://doi.org/10.1007/s10597-011-9393-x

Hines, A., Cohen, E., Tran, D. T., Lee, P., \& Phu, T. V. (2010). The development of social work in Vietnam: The role of international collaboration. Social Work Education, 29(8), 910-922. https://doi.org/10.1080/02615479.2010.517019

Hugman, R., Durst, D., Le Hong, L., Nguyen, T. T. L., \& Nguyen, T. H. (2009). Developing Social Work in Vietnam: Issues in Professional Education. Social Work Education, 28(2), 177-189. https://doi.org/10.1080/02615470802243087

Mai, H. T. (2011). Some issues of Social Work practice in the faculty of Sociology, University of Social Sciences and Humanities currently, in 20 years of Faculty of Sociology: Achievements and Challenges, Hanoi, Vietnam National University Press.

Ministry of Health. (2011). Decision on 'Approving the project to develop health social work, 2011-2020', Hanoi, Ministry of Health.

Ngo, K. K. (2009). Social Work education in Vietnam, in Proceedings of the National Conference on Development of Social Work in Vietnam, Hanoi, Statistic Publishing House.

Nguyen, V. H. (2009). Proposal for the development of social work, 2010-2020, in Proceedings of the National Conference on Development of Social Work in Vietnam, Hanoi, Statistical Publishing Hous.

Nguyen, V. H. (2014). Reviewing the implementation of Project 32 on developing social work profession between 2010 and 2014, in Reality and integration of social work development in Vietnam, Hanoi, Thanh Nien Publishing House.

Nguyen, H. T. K. (2011). Faculty of Sociology: Achievement of 20 year education in Sociology and Social Work, in 20 years of faculty of Sociology: Achievements and Challenges (pp. 3-15), Hanoi, Vietnam National University Press.

Nguyen, T. T. L. (2011). Developing a social work profession embracing cultural traditions and authenticity, in Proceedings to the Conference on Social Work in the Context of Market Economy and Global Integration, Hanoi, University of Social Sciences and Humanities.

Nguyen, Q., \& Anderson, L. (2005). Vietnamese Americans' attitudes toward seeking mental health services: Relation to cultural variables. Journal of Community Psychology, 33(2), 213-231. https://doi.org/10.1002/jcop.20039

Nguyen, L. T. T., Hugman, R., \& Briscoe, C. (2010). Moving towards an "indigenous" social work education in Vietnam. Social Work Education, 29(8), 843-854. https://doi.org/10.1080/02615479.2010.517013

Oanh, N. T. (2002). Historical development and characteristics of social work in today's Vietnam. International Journal of Social Welfare, 11(1), 84-91. https://doi.org/10.1111/1468-2397.00199

Phan, T. (2000). Investigating the use of services for Vietnamese with mental illness. Journal of Community Health, 25(5), 411-425. https://doi.org/10.1023/A:1005184002101

Vietnam Prime Minister. (2010). Decision to approve Project 32 to develop social work profession in Vietnam. http://thuvienphapluat.vn/van-ban/Van-hoa-Xa-hoi/Quyet-dinh-32-2010-QD-TTg-phe-duyet-De-an-phat-trien-ngh e-cong-tac-xa-hoi-giai-doan-2010-2020-102910.aspx

\section{Copyrights}

Copyright for this article is retained by the author(s), with first publication rights granted to the journal.

This is an open-access article distributed under the terms and conditions of the Creative Commons Attribution license which permits unrestricted use, distribution, and reproduction in any medium, provided the original work is properly cited. 